\title{
Long-distance bound local anaphors in Korean-An empirical study of the Korean anaphor caki-casin
}

\author{
Ji-Hye Kim ${ }^{*}$, James H. Yoon ${ }^{1}$ \\ Department of Linguistics, 4080A Foreign Languages Building, School of Languages, Cultures, and Linguistics, \\ University of Illinois, Urbana-Champaign, Urbana, IL 61801, USA
}

Received 21 March 2008; received in revised form 14 October 2008; accepted 14 October 2008

Available online 30 December 2008

\begin{abstract}
In this paper we argue that the Korean anaphor caki-casin, taken thus far to be a local anaphor, can be bound long-distance in certain cases as an exempt anaphor. We make this argument on the basis of an experimental study where the subjects were asked to judge the grammaticality of sentences with long-distance bound caki-casin and to choose between the strict and sloppy readings in contexts of ellipsis/proform. A majority of subjects accepted long-distance bound caki-casin and preferred strict readings, indicating that long-distance bound caki-casin is behaving as an exempt anaphor. Speakers who accepted sentences with longdistance bound caki-casin were sensitive to logophoric factors that are known to influence exempt binding. These results imply that the core vs. exempt binding distinction (Pollard and Sag, 1992, 1994; Reinhart and Reuland, 1993) exists even in languages like Korean with a rich inventory of anaphors-local and long-distance-suggesting that the core-exempt dichotomy is orthogonal to the local vs. long-distance property of anaphors (Cole et al., 2001; Huang and Liu, 2001). More generally, the results indicate that both grammar and the interfaces are involved in anaphor binding.
\end{abstract}

(C) 2008 Elsevier B.V. All rights reserved.

Keywords: Anaphor; Logophoricity; Exempt binding; Korean

\section{Introduction}

In this paper we argue that the Korean anaphor caki-casin, taken thus far to be a local anaphor, can be bound longdistance in certain cases as an exempt anaphor when appropriate extra-grammatical conditions are satisfied. We make this argument on the basis of an experimental study where the subjects were asked to judge the grammaticality of sentences with long-distance bound caki-casin and to choose between the strict and sloppy readings in contexts of ellipsis/proforms. A majority of subjects accepted long-distance bound caki-casin and strict readings became easily available in contexts of ellipsis/proforms, indicating that long-distance bound caki-casin is behaving as an exempt anaphor. In addition, speakers who accepted sentences with long-distance bound caki-casin were sensitive to logophoric factors that are known to influence exempt binding. These results imply that the core vs. exempt binding

\footnotetext{
* Corresponding author at: Information Management Research Center, SungKyunKwan University, Hoam Hall, 604 Myungryundong 3-53, Chongno-gu, Seoul 61801, Republic of Korea. Tel.: +82 1045362731.

E-mail addresses: jkim38ster@gmail.com (J.-H. Kim), jyoon@uiuc.edu (J.H. Yoon).

${ }^{1}$ Tel.: +1 2172443055 .
} 
distinction (Pollard and Sag, 1992, 1994; Reinhart and Reuland, 1993) exists even in languages like Korean with a rich inventory of anaphors-local and long-distance-suggesting that the core-exempt dichotomy is orthogonal to the local vs. long-distance property of anaphors (Cole et al., 2001, 2006; Huang and Liu, 2001). More generally, the results indicate that both grammar and the interfaces are involved in anaphor binding.

The organization of the paper is as follows. In section 2, we review the theoretical background on Korean binding. In section 3, we explain the method of the empirical study used to investigate our research questions and present the results of the experiments. Section 4 deals with further implications and future directions for research.

\section{Korean anaphors: an overview}

\subsection{Korean anaphors: properties}

While the long-distance anaphor (LDA) caki has been the subject of much previous research on Korean anaphors (Yang, 1983), Korean also possesses several other anaphors, such as casin, pronoun-casin, and caki-casin. The four different anaphors can be used interchangeably in many contexts, such as in (1) below.

$$
\begin{array}{llll}
\text { John-un } & \text { caki/casin/caki-casin/ku-casin-uy } & \text { yakcem-ul cal molun-ta } \\
\text { J-top } & \text { self-gen } & \text { weakness-acc } & \text { well } \\
\text { 'John doesn't know his own weaknesses well.' }
\end{array}
$$

$K u$ in $k u$-casin above is a 3rd person pronoun when it occurs by itself. Both caki and casin are of Sino-Korean compounds and literally mean 'one's own body'. As shown below in (2), caki behaves like pronouns in terms of its position within complex anaphors, as it occupies the initial, non-head position, while casin occurs in the final, head position.

However, the anaphors are not always interchangeable. One dimension along which the anaphors differ regards the properties of antecedents. Anaphors based on caki (that is, caki and caki-casin) cannot easily take first or second person antecedents, whereas third-person antecedents are fine (2a vs. $2 \mathrm{~b}, \mathrm{c}){ }^{2}$ By contrast, casin $(2 \mathrm{a}-\mathrm{c})$ and pronoun-casin $(3 \mathrm{a}-\mathrm{c})$ are compatible with antecedents in all three persons. Illustrative data are given below.

$\begin{array}{lllll}\text { (2) a. John-un } & \text { caki/casin/caki-casin-uy } & \begin{array}{l}\text { swuhak } \\ \text { math }\end{array} & \begin{array}{l}\text { sillyek-ul cal } \\ \text { ability-acc well }\end{array} & \text { alko iss-ta } \\ \text { John-top } & \text { self-gen } & \text { prog-decl }\end{array}$
b. Ne-nun ??caki/casin/??caki-casin-uy swuhak sillyek-ul alko iss-ni? You-top self-gen math ability-accknow prog-Q 'Do you know your own ability in math?'

$\begin{array}{lllll}\text { c. Na-nun } & * \text { ? caki/casin/*?caki-casin-uy } & \text { swuhak } & \text { sillyek-ul cal alko issta } \\ \text { math } & \text { ability } & \text { well know prog } \\ \text { 'I am well aware of my ability in math.' } & & & & \end{array}$

\footnotetext{
${ }^{2}$ Reflexives based on caki also have a deictic usage to refer to the addressee (second person) for many speakers. This may explain why these reflexives are not completely out with second person antecedents (cf. $2 \mathrm{~b}$ ). Speakers who accept (2b) may be interpreting the caki-based reflexives deictically.

As the data show, caki-based reflexives are not completely out with first person antecedents. This means that we cannot simply assume that caki is inherently 3rd person. The preference for third person antecedents that most uses of caki-based anaphors are subject to may stem from something like point of view (Oshima, 2006).

The anaphors, except pronoun-casin, can also be used with generic, arbitrary, interpretation (meaning 'oneself'). The generic usage is more common with caki-based forms than casin. We take generic anaphors to be 3rd Person.
} 
(3) a. John-un ku-casin-uy mwunceycem-ul cal alko issta J-top him-self-gen problem-acc well know prog

'John is well aware of his own shortcomings.'

b. Ne-nun ney-casin-uy mwunceycem-ul cal alko iss-ni? You-top your-self-gen problem-acc well know is

'Are you well aware of your own shortcomings?'

c. Na-nun nay-casin-uy mwunceycem-ul cal alko issta

You-top my-self-gen problem-acc well know is

'I am well aware of my own shortcomings.'

All anaphors in Korean prefer animate antecedents. Thus, inanimate, or group-denoting nouns are marginal as antecedents of anaphors, even though they are third-person.

(5) *?Wiywenhoy-ka caki/caki-casin/casin/ku-casin-uy kyelcengsahang-ul wuli-eykey

Committee-nom self-gen decisions-acc we-dat

thongpohayssta

informed

'The committee informed us of its decision.'

Singular inanimates are likewise bad when anteceding anaphors, unless personified as in fairy-tale contexts.

(6) \# Ku namwu-ka caki/caki-casin/casin/ku-casin yeph-ey seywecie iss-nun That tree-nom self beside-loc parked be-adnom catongcha wuy-lo nemeci-ess-ta

car top-loc fall-pst-decl

'The tree fell on top of the car parked next to it(self).'

A second dimension along which they differ is long-distance binding. Caki and casin are known to allow longdistance antecedents quite freely. In contrast, the consensus in the literature is that caki-casin and pronoun-casin are primarily local anaphors (Yoon, 1989; Cole et al., 1990). A similar position has been advanced regarding the Japanese anaphor system in Katada (1991), where the Japanese counterparts to caki-casin and pronoun-casin in Korean, zibun-zisin and pronoun-zisin, are taken to be local anaphors in contrast to zibun, which is taken to be an LDA. Kang's (1998) corpus-based study showed that caki-casin occurs primarily as a local anaphor, lending support to earlier theoretical research. ${ }^{3}$

For the purposes of this paper, we do not need to resolve the issue of what determines whether a given anaphor will function primarily as a long-distance anaphor. This is because our focus in this paper is on the long-distance usages of an anaphor that has been taken thus far to be a local anaphor-caki-casin. We will argue that even when caki-casin is long-distance bound, it is not a genuine long-distance anaphor but a local anaphor that is converted into pronominal, or exempt anaphor, usage, according to the typology of long-distance reflexives in Cole et al. (2001, 2006). As Cole, et al. observe, the converted, or exempt anaphors as we shall call them, must satisfy discourse conditions in order to be licensed and this is indeed what we find with LD-bound caki-casin.

We will therefore leave unresolved the question as to whether long vs. local binding behavior can be predicted on the basis of inherent properties of anaphors and instead turn to the distinction between core vs. exempt binding.

\footnotetext{
${ }^{3}$ Specifically, Kang examined accusative-marked forms of the three reflexives in his corpus (Korea University Corpus of Korean, Collection I) and found the following (Kang, 1998:183)

$\begin{array}{lccc} & \text { caki-acc } & \text { casin-acc } & \text { caki-casin-acc } \\ \text { Local } & 151 & 311 & 66 \\ \text { Long-distance } & 165 & 123 & 5 \\ \text { Total } & 316 & 434 & 71\end{array}$
}

These figures support the intuition of many native speakers about the local vs. long-distance binding potential of various anaphors in Korean. 


\subsection{Core vs. exempt anaphors}

That local anaphors are not restricted to contexts of local binding has been pointed out in the work of Pollard and Sag (1992) and Reinhart and Reuland (1993), among others. The perspective on anaphor licensing adopted in these works is quite different from the line of research that emanates from what has been dubbed the Standard Binding Theory (Chomsky, 1980, 1981). Contrary to Standard Binding Theory, these researchers take the job of licensing of anaphors not to rest entirely with grammar-internal principles. Only certain anaphors need to be licensed grammar-internally, while others need not. Thus, syntactic Binding Theory underdetermines the distribution and interpretation of anaphors.

In this approach, anaphors that need to be licensed grammar-internally are those that have a superior co-argument (Pollard and Sag, 1992) or a Subject/Specifier within a Complete Functional Complex (CFC) in the sense of Chomsky (1986). ${ }^{4}$ All other anaphors are licensed by extra-grammatical mechanisms. The term core anaphor (or grammatical anaphor) designates the former, while the term exempt anaphor (or logophor) refers to the latter. The system of grammar-internal binding principles can correspondingly be termed grammatical binding.

An important question for this line of research is the following: how do we know that a given anaphor is exempt since languages do not have dedicated forms of exempt anaphors?

The first indication that an anaphor is exempt is its occurrence in contexts without a minimal Subject (or superior co-argument), as stated in the previous paragraph. However, this is not the only diagnostic property. Exempt anaphors have been found to display a cluster of properties that distinguish them from core anaphors, such as the following:

(8) a. Exempt anaphors may be unbound (or discourse-bound).

b. Exempt anaphors do not need c-commanding antecedents.

c. Exempt anaphors may be long-distance bound.

d. Exempt anaphors allow strict readings in contexts of ellipsis/proforms.

Properties (8a-c) can be illustrated with English exempt anaphors. English, a language that is generally thought to lack LDAs, allows its anaphors to be bound long-distance or be discourse-bound in certain cases, as seen in (9a) and (9b) below. In addition, c-command, which is required in core binding, is not necessary between exempt anaphors and their antecedents (cf. 9c). ${ }^{5}$ By contrast, anaphors that cannot be construed as exempt (in virtue of the presence of a locally commanding Specifier in the minimal CFC) cannot be licensed in similar contexts. This is seen in $\left(9 \mathrm{a}^{\prime}-9 \mathrm{c}^{\prime}\right)$. The anaphors in $\left(9 \mathrm{a}^{\prime}, \mathrm{c}^{\prime}\right)$ are core anaphors because of the presence of a Possessor within the DP, and cannot take long-distance antecedents.
a. Bill remembered that the Times had printed [a picture of himself] in its Sunday edition.
$a^{\prime}$. ??Bill remembered that the Times had printed [Mary's picture of himself] in its Sunday edition.
b. [Physicist like yourself] are a godsend.
c. [Incriminating pictures of himself published in the Times] have all but eliminated John's chances of being promoted.
$c^{\prime}$. *[Mary's pictures of himself published in the Times] have all but eliminated John's chances of being promoted.

\footnotetext{
${ }^{4}$ By this logic, anaphors that are subjects should be licensed as exempt anaphors, so that (i) should be well-formed as an instance of exempt binding: (i) *John admits that himself is to blame for the equipment failure

Pollard and Sag's (1992) take on (i) is that it is out for reasons independent of binding: namely, the anaphor should be nominative-marked but there are no nominative anaphors in English.

This account then predicts that when case is not at stake, TSC violations should become acceptable so long as they can be construed as instances of exempt binding. The prediction seems to be borne out.

(ii) ?John thinks that [Bill and himself]/[himself and Bill] are to blame for the accident

(iii) ?The boys think that each other are to blame for the mess

Chomsky (1981) accounted for (ii) through a specially crafted theory of GCs intended to allow TSC violations just in case an anaphor is contained within a (nominative-marked) Subject (through the provisions of the Accessibility Condition that is in turn built on the so-called $i$-within- $i$ condition). However, the account does not extend to (iii), which, though marginal, has long been noted to be much better than (i). Chomsky's (1986) suggestion that (i) is to be assimilated to the that-trace effect (on the LF-moved anaphor) does not work either, since the presence or absence of the complementizer has no effect on (i). Therefore, there is no viable account of the well-formedness of (i) and (ii) in standard Binding Theory.

${ }^{5}$ A well-known account of backward binding by non-c-commanding antecedents that tries to bring such binding within the fold of core binding is Belletti and Rizzi (1988). However, the predicate in (9c) is not a psych predicate, so that their account cannot be extended to it. In addition, the antecedent John does not c-command the anaphor at D-structure even if we allow an unaccusative parse for the main clause predicate in (9c).
} 
Cole et al. (2001, 2006) (see also Runner et al., 2002) propose another diagnostic for core vs. exempt anaphors based on sloppy vs. strict readings in contexts of ellipsis/proforms. This is shown below. The elliptical VP in the second sentence in (10) receives a sloppy interpretation, that is, as meaning 'Bill defended Bill'. The strict reading ('Bill defended John') is nearly impossible to obtain. This indicates that locally bound core anaphors are interpreted sloppily (as bound variables) in contexts of ellipsis/proforms.

John defended himself against the committee's accusations. So did Bill.

However, speakers can assign a strict, or referential, interpretation to the missing VP in (11a), where the second sentence can be interpreted as meaning that 'Bill also thinks that an article written by John caused the uproar'. The strict interpretation is available in (11b) as well, which also contains an exempt anaphor.

a. John thinks that an article written by himself caused the uproar. So does Bill.

b. John thinks that Susan and himself are to blame for the accident. So does Bill.

Both sloppy and strict readings are available in exempt binding, whereas strict readings are highly degraded, if not altogether impossible, in case of core binding. Therefore, we can use the availability of strict readings in ellipsis/ proform contexts as another diagnostic of exempt anaphors.

Now, while exempt anaphors escape the strictures of syntactic conditions that constrain core anaphors, their licensing is subject to discourse-pragmatic conditions. Conditions that fall under the rubric of logophoricity (Sells, 1987; Huang and Liu, 2001, among others) constrain exempt anaphors. ${ }^{6}$ Specifically, an exempt anaphor is felicitous if its antecedent is a logophoric center. Following Sells (1987), we posit three such logophoric centers-SOURCE, SELF, and PIVOT. ${ }^{7}$

The contrast shown below can be understood in this light. The structural distance between and relative configurations of the antecedent and anaphor (i.e., lack of c-command) are identical in the sentences and yet there is a contrast among the three sentences.

(12) a. [Incriminating pictures of himself published in the Times] have been worrying John for some time.

b. ?[Incriminating pictures of himself published in the Times] have all but eliminated John's chances of being promoted.

c. *?[Incriminating pictures of himself published in the Times] accidentally fell on John's head.

The judgments seem to reflect the ease with which John can be identified as a logophoric center. In (12a), John is a SELF (and so also a PIVOT), in the sense of Sells (1987), while in (12b) and (12c) it can only be a PIVOT. (12b) is better than $(12 \mathrm{c})$ because it is easier to construe this sentence as being reported from the point of view of John, compared to the third.

\subsection{Exempt binding in languages with long-distance anaphors}

Since properties of exempt/logophoric binding have been investigated mostly for English, a language that lacks genuine LDA's, we might hypothesize that if a language possesses a rich inventory of anaphors, the core-exempt binding distinction may not be realized in such a language. This is because it is conceivable that some anaphors in the inventory function exclusively in contexts of grammatical binding while others are devoted to contexts of exempt or logophoric binding.

Korean is a language with a rich anaphor inventory that includes both local and long-distance anaphors. Given the core-exempt distinction in anaphor binding, a number of questions invite themselves about Korean: What is the

\footnotetext{
${ }^{6}$ However, as a reviewer reminds us, even genuine long-distance anaphors may be subject to discourse conditions (Cole et al., 2001, 2006). Thus, the existence of discourse conditions by itself does not establish that the anaphor in question is an exempt anaphor. That is why we also employed the strict/sloppy readings as an additional diagnostic.

${ }^{7}$ Sells (1987) gives the following characterizations of these roles (Sells, 1987:457):

SOURCE: one who is the intentional agent of the communication

SELF: one whose mental state or attitude the content of the preposition describes

PIVOT: one with respect to whose (space-time) location the content of the proposition is evaluated

It is important to clarify that that Sells (1987) did not make the core-exempt distinction. We are reinterpreting his conclusions in light of this distinction, following Huang and Liu (2001) who demonstrate convincingly that core anaphors do not require discourse-pragmatic conditions to be licensed.
} 
division of labor among different anaphors? Since long-distance anaphors in languages like Korean (caki in Korean and ziji in Chinese) have also been characterized as logophors in some approaches (Sells, 1987; Huang and Liu, 2001; Iida, 1992; Huang, 2000), are local anaphors such as caki-casin and pronoun-casin restricted to contexts of grammatical binding? Or is the core/grammatical vs. exempt/logophoric dichotomy of anaphors orthogonal to the long-distance vs. local property of anaphors? And if local anaphors can be licensed as exempt anaphors, are the conditions similar to those that hold in the licensing of exempt anaphors in languages like English?

Answers to these questions are important and will enhance the theoretical understanding of anaphor binding in UG, as well as the possible correlates, if any, of exempt binding in languages where it is attested.

As a first step in a cross-linguistic investigation of anaphors within an approach that posits the core-exempt distinction, we wanted to investigate whether anaphors previously claimed to be restricted to local binding in languages with both local and long-distance anaphors can be licensed as exempt anaphors. Since the ability of an otherwise local anaphor to take long-distance antecedents is one of the claimed diagnostics of exempt binding (cf. 8c), we focused our attention primarily on whether native speakers of Korean judge sentences with the long-distance bound local anaphor caki-casin to be acceptable and if so, to determine whether they are treating it as core or exempt anaphor by asking subjects to choose between the strict and sloppy interpretations in ellipsis/proform contexts in the sentences where caki-casin is longdistance bound. We also varied the sentences containing long-distance bound caki-casin in terms of factors known to effect logophoricity. That is, while some sentences with LD-bound caki-casin had an easily identifiable logophoric antecedent, others did not. The rationale was to discover if logophoric factors facilitate the acceptance of LD-bound caki-casin.

We chose to investigate these questions through an experimental syntactic study. The primary rationale for conducting an experimental study comes from the recognition that individual judgments about anaphor binding in languages like Korean are notoriously unreliable, except in the simplest cases. This is as it should be, since according to the best current understanding, judgments about anaphors involve making inferences about discourse-pragmatic factors involved in logophoricity and computing the core-exempt distinction. Therefore, along with corpus-based studies such as Kang (1998), carefully designed experimental studies are called for to establish a baseline of judgments about various anaphors in Korean. Experimental syntactic investigations of a variety of phenomena have yielded insights that were not obtainable under intuition-based studies. ${ }^{8}$ In addition to employing experimental syntactic methodology, we believe that our research is one of the few that investigates core vs. exempt binding for Korean anaphors in a systematic way.

\section{Empirical study}

\subsection{Research questions}

The specific research questions we addressed in our study are the following:

1) Do native speakers of Korean accept long-distance binding of the local anaphor caki-casin?

2) If they do, do they treat it as a core or exempt anaphor? The answer to this question devolves to the resolution of the following two sub-questions:

2-1) Are long-distance antecedents of caki-casin optimal when they carry a typical logophoric role?

2-2) Does the strict reading become available in contexts of ellipsis/proforms? ${ }^{9}$

The first question attempts to find out if native speakers of Korean accept long-distance bound caki-casin. Under the assumption that caki-casin is primarily a local anaphor, as reported in theoretical and corpus studies (Kang, 1998), but that local anaphors can be converted into exempt anaphors that can take long-distance antecedents, we predict that native speakers will accept long-distance bound caki-casin if they are able to analyze it as an exempt anaphor.

\footnotetext{
${ }^{8}$ For example, Han et al. (2007) discovered through an experimental study that judgments about relative scope of quantifiers and negation in Korean, another area rife with conflicting judgments in the literature, show a bimodal distribution, with one group of speakers consistently favoring surface scope but another allowing inverse scope. On the basis of these results, they hypothesize that there may be more than one grammar among speakers of Korean. It should be obvious that an intuition-based study could not have yielded such results.

${ }^{9}$ As a reviewer points out, the expectation should be that in contexts of exempt binding, strict readings should become available, and not that strict readings should be preferred over sloppy readings. This is so since exempt anaphors are anaphors 'converted' to become like pronouns (Cole et al., 2001, 2006). The important contrast between locally bound reflexives and pronouns is that the latter allows both strict and sloppy readings in ellipsis/ proform contexts while the former disallows strict readings, and not that strict readings are more dominant than sloppy readings with pronouns.
} 
This leads us to the second question, which seeks to investigate whether long-distance bound caki-casin is a grammatical or an exempt anaphor. This question is answered on the basis of two diagnostics for exempt anaphors.

First, if we find that long-distance bound caki-casin is sensitive to known logophoric factors, it would indicate that speakers are treating it as an exempt anaphor. Specifically, since not all logophoric roles are created equal (Sells, 1987; Huang and Liu, 2001), as some roles (SOURCE) are more canonical than others (PIVOT), we expect differences in judgments depending on the logophoric role of the long-distance antecedent of caki-casin. We also expect LD-bound caki-casin to be more acceptable in sentences with clearly identifiable logophoric antecedents as opposed to those where such identification is difficult.

Another test of core vs. exempt anaphors comes from strict vs. sloppy identity readings in ellipsis/proform contexts mentioned earlier. If we should find that speakers who accept long-distance bound caki-casin allow strict readings, we can conclude that they are treating LD-bound caki-casin as an exempt anaphor.

\subsection{The experiment}

\subsubsection{Hypotheses and predictions}

Regarding the questions identified above, we hypothesized the following:

Hypothesis. Korean native speakers will accept sentences with long-distance bound caki-casin by taking it as an exempt anaphor.

In terms of the expected results of the experiment, our specific predictions were as follows:

1) The average grammaticality score that the subjects give for sentences with long-distance bound caki-casin will be closer to the 'grammatical' rather than the 'ungrammatical' end of the grammaticality judgment scale.

2) There should be differences in the degree of grammaticality according to the logophoric roles of the long-distance antecedent of caki-casin. That is, the more canonical the logophoric role of the antecedent, the higher the degree of grammaticality should be.

3) A subject who accepts long-distance bound caki-casin should also allow strict readings in ellipsis/proform contexts.

\subsubsection{Method}

3.2.2.1. Participants. Forty-three Korean monolingual speakers (ages ranging between 42 and 58) residing in and around Seoul, South Korea participated in the experiment. They grew up in South Korea as monolinguals and none of the subjects had lived longer than a month in a foreign country. ${ }^{10}$

3.2.2.2. Task and materials. The task used in the experiment was a Grammaticality Judgment Task using the 5-point Likert scale, coupled with a Preferential Sentence Interpretation Task based on Maling et al. (2000). Thus, each task consisted of two parts. The first part of the task asked the subjects to judge the degree of grammaticality of a sentence where caki-casin occurs with a long-distance antecedent. This part was designed to investigate research questions 1 and 2-1 by comparing different types of sentences with respect to the type of binding and distinct logophoric roles of antecedents. The second part was designed to examine research question 2-2, the strict vs. sloppy readings of longdistance bound caki-casin in the context of ellipsis/proforms.

The test materials consisted of 100 items-62 target items and 38 non-target items. The target items were composed of 2 types of Korean sentences violating TSC (cf. see (14)) with 5 tokens in each type, 9 types of Korean sentences attesting both TSC and SSC violations, again with 5 tokens in each type. Sentences with only TSC violation (10 tokens) exemplify core binding, while the remaining 52 tokens that violate both TSC and SSC were meant to exemplify various types of exempt binding. The sentences with TSC and SSC violations were constructed to reflect various combinations of the factors (i.e., logophoric role (cf. see (15)-(18); subject vs. non-subject antecedent; c-commanding vs. non-c-commanding antecedent; and varying case-marking/grammatical function of the anaphor).

\footnotetext{
${ }^{10}$ The reason for the advanced age of the subjects is that among younger Koreans, it is difficult to find subjects who have not spent a month or two abroad. And while the subjects in the age group we studied received English instruction from 7th grade on, they have little active competence in English, so that the question of transfer/interference from L2 is minimal, if not altogether non-existent. The situation is different in the case of the younger generation with a much higher degree of competence in English.
} 
There were two types of non-target items. The first type of non-target item (10 tokens) consisted of grammatical sentences containing caki-casin with which we wanted to investigate some questions that were not directly addressed in the research questions of the study. 5 sentences contained multiple potential antecedents of caki-casin. Responses to these would enable us to test how the subjects will respond when there is more than one potential antecedent.

The remaining 5 sentences had Pivots who were not conscious of the action described in the sentences. We wanted to know if consciousness had an effect on exempt binding. However, since we found no effect of consciousness, these were discarded from our analysis. ${ }^{11}$

The remaining 28 non-target items were ungrammatical fillers/distractors. They were composed of ungrammatical sentences that contained anaphors other than caki-casin, or those that had caki-casin but were ungrammatical for reasons unrelated to binding.

We shall now describe the design of the target items in more detail.

In order to test research question 1 (i.e., whether native speakers of Korean accept long-distance binding of the local anaphor caki-casin), sentences where an anaphor was forced to seek a long-distance antecedent were compared to those containing locally bound anaphors. We constructed the target items so that caki-casin did not have a potential antecedent within the minimal CFC.

An example sentence used as a target item is given in (13). Caki-casin in (13) is forced to take the matrix subject Heera as antecedent, in violation of both TSC and SSC. This is so since the local subject tongchanghoy 'the alumni association' is inanimate and hence not a possible antecedent of caki-casin.

(13) Heera $_{\mathrm{i}}-$ nun [tongchanghoy ${ }_{\mathrm{j}}-\mathrm{ka}$ [caki-casin ${ }_{\mathrm{i}}-\mathrm{i}$ taumcwu-ey kyelhonhana-nun

Heera-top alumni.assoc-nom self-nom next week get-married-rel

sasil]-ul imi palphyohayssta]-ko malhayssta

fact-acc already announced-comp said

'Heera said that the alumni association already announced the fact that she (self) would get married next week.'

Sentences exemplifying exempt binding were compared to sentences exemplifying core binding, where only the TSC is violated. (14) is an example. In (14), the anaphor caki-casin is bound by an antecedent Jieuni, which is outside the minimal clause that contains the anaphor, but not separated from it by an intervening subject.
[Jieuni $i_{\mathrm{i}}-\mathrm{ka}$ Sanghoon-eykey
Jieuni-nom Sanghoon-dat
[ipen hakki-ey-nun
caki-casin $_{\mathrm{i}}$-i kkok
iltung-ul
this semester-loc-top self-nom
$1^{\text {st }}$.place-acc do-asp-decl-comp say-past-decl-comp I-top know-comp be-decl.
'I know that Jieun said to Sanghoon that she (self) would be at the top of her class this semester.'

Following Huang and Liu (2001) for similar sentences in Chinese, we made the assumption that this sentence type falls under core binding for Korean but under exempt binding in languages like English, since English does not allow core anaphors to violate TSC, as noted earlier. This type of sentence is designed to serve as the basis for comparison with sentences exemplifying Korean exempt binding in their grammaticality scores as well as sloppy vs. strict reading in contexts of ellipsis/proforms. ${ }^{12}$

\footnotetext{
${ }^{11}$ The non-target items that were grammatical were not included in the calculation of grammaticality ratings for distractors given in Table 1 in section 3.3 .

${ }^{12}$ As sentences exemplifying core binding, we did not use sentences where caki-casin was bound by a clause-mate antecedent, i.e., sentences where neither the TSC nor the SSC is violated. Adjusted for length, such a sentence would look like (i) below, where the local subject of the anaphor is the only possible antecedent (the non-local subjects do not match the anaphor in features):

(i) Ney-ka Cheli-ka caki-casin-uy mwuncey-lul molunta-ko sayngkakhanta-ko na-nun tulessta

you-nom C-nom self-gen problem-acc unaware-comp think-comp I-top heard

'I heard that you think that Cheli is unaware of his own problems.'

The reason we did not use such sentences was that the distance between the antecedent and the anaphor is too close, whereas in core binding sentences with TSC violation the antecedent and the anaphor are separated by a clause boundary (as well as by a matrix non-subject). Our concern was to control for the item effect.

However, as we shall see, this turned out to be a gap in the experimental design, since speakers found caki-casin in TSC-violating sentences to allow strict readings quite freely. In fact, as we shall suggest, TSC-violating caki-casin is very likely an exempt anaphor. If so, then, contrary to our initial expectations, we did not have experimental controls for genuine instances of core-bound caki-casin. We will return to this issue in section 3.4.
} 
Sentences with TSC violations were made longer than bi-clausal. We did so to avoid the possible distortion of the pattern of the results caused by the item effect (i.e., one specific type of item forcing participants to respond in a certain way) and to ensure a similar amount of overall processing time across the range of test items.

To test research question 2-1 (i.e., whether LD antecedents of caki-casin are optimal when they carry a typical role), we constructed several target sentences representing Korean exempt binding according to the logophoric roles of the LD antecedents. We describe each sentence type below.

\section{SOURCE:}

The example sentence in (13) repeated below as (15) represents a sentence with a long-distance SOURCE antecedent for caki-casin. The LD antecedent Heera is the speaker of the embedded proposition and carries the logophoric role of SOURCE.

(15) Heera $a_{i}-n u n$ [tongchanghoy ${ }_{j}-k a \quad\left[\right.$ caki-casin $_{i}-\mathbf{i}$ taumcwu-ey kyelhonhana-nun

Heera-top alumni.assoc-nom self-nom next week get-married-rel

sasil]-ul imi palphyohayssta]-ko malhayssta

fact-acc already announced-comp said

'Heera said that the alumni association already announced the fact that she (self) would get married next week.'

\section{SELF:}

(16) is a sentence containing a long-distance SELF antecedent for caki-casin. In this sentence, the intervening subject na 'I' cannot be the antecedent of caki-casin, due to a mismatched person feature. The matrix subject Kicwu is the only possible antecedent. Kicwu is the Experiencer of the predicate mit-ta 'believe' and denotes the person one whose mental state is represented throughout the sentence; therefore, its logophoric role is SELF.
$\mathbf{K i c w u}_{\mathrm{i}}$-nun [nay-ka khun ton-ul
pat-ko
[caki-casin ${ }_{i}-\mathrm{i}$ swumki-ko iss-ten
Kicwu-top I-nom big money-acc get-conj self-nom hide-comp be-rel
pimil]-ul sangtay-phyen hoysa-ey phal-ass-ta]-ko mit-ko iss-ta
secret-acc opposite-side company-dat sell-pst-decl-comp believe be-decl

'Kicwu believes that I sold the secret that she(=self) was hiding to a rival firm after accepting a huge bribe.'

\section{PIVOT:}

Sentences containing PIVOT antecedents were constructed following Sells (1987), who used directional auxiliaries $o$-ta 'come' and ka-ta 'go' to identify PIVOTs. (17) is an example. (17) has more than one third-person NP. However, the directional auxiliary $o$-ta 'come' in the adjunct clause implies that the matrix subject Yenghi is the deictic center, as Chelswu is described as coming toward her. Thus, Yenghi is the PIVOT of the sentence.

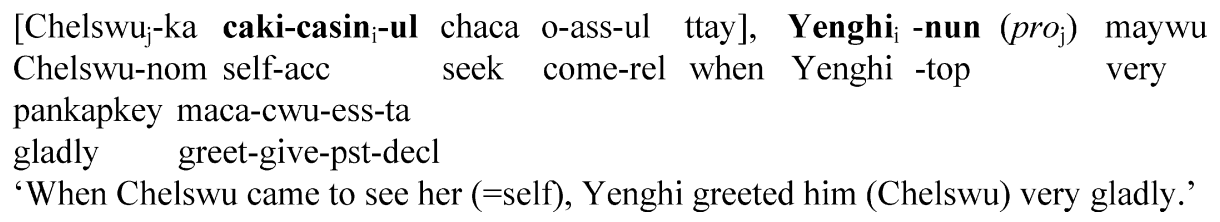

If the auxiliary ka-ta 'go' is used instead of o-ta 'come', Yenghi is harder to construe as PIVOT, since the action in the adjunct clause is described from the perspective of the subject Chelswu.

However, it is important to note that among the three logophoric roles in Sells (1987), PIVOT is the most flexible and elusive: within a sentence, almost any entity can serve as PIVOT according to point of view from which the event described by the sentence is presented. It is even possible for POV to shift between the main clause and the adjunct clause. An example of such a sentence is presented in (18) below.

\section{LESS LOGOPHORIC ANTECEDENTS:}

In (18), the auxiliary ka-ta 'go' is used in the adjunct clause, which indicates that the POV is that of the referent of the subject of the adjunct clause, haksayngtul 'students'. However, 'students' cannot be construed pragmatically as the antecedent of the anaphor in the overall context of this sentence. Hence, when the matrix clause is parsed and the subject Chelswu is encountered, the POV has to shift to that of Chelswu in order for it to serve as the antecedent of the exempt anaphor contained in the adjunct clause. 
[Haksayngtul $\mathrm{j}_{\mathrm{j}} \mathrm{i}$ caki-casin $_{\mathrm{i}}-\mathrm{ul}$ chac-ule kass-ul ttay], Chelswu $\mathrm{i}_{\mathrm{i}}$-nun pang-eyse students-nom self-acc seek-to went-rel when Chelswu-top room-loc chayk-ul ilk-ko iss-ess-ta-ko malhayss-ta

book-acc read-comp be-pst-decl-comp said-decl.

'Chelswu said that he (self) was reading a book when the students went to see him.'

Since in parsing this sentence a shift in POV between the adjunct and the main clauses is necessitated in order to obtain the requisite binding interpretation, we can imagine that the binding relation in this type of sentence will be more difficult to obtain compared to sentences that do not require a POV shift.

For reasons such as these, sentences such as (18) are categorized as Less Logophoric, or lower in the degree of logophoricity, rather than as non-logophoric. We expect this type of sentence to be judged less grammatical but not completely out, with the indicated binding interpretation when compared to sentences containing clearly identifiable logophoric centers. ${ }^{13}$

Research question 2-2 (i.e., whether the strict reading in VP ellipsis/proform contexts becomes available in exempt binding) was tested by having speakers judge the interpretation of a sentence containing ellipsis/proform immediately following the sentence whose grammaticality the subjects were asked to judge.

An example of a test item translated into English is given in (19). Following a target item testing the degree of grammaticality of LD exempt binding, a sentence containing ellipsis/proform is given. The speakers were asked to rate the grammaticality of the first sentence and then select the most appropriate interpretation among the sloppy reading (A), the strict reading (B), or neither (C). The speakers were asked to choose no more than one answer for each item. If there is more than one possible interpretation, the speakers were instructed to choose the more salient interpretation among the choices. For speakers who judge a sentence with LD-bound exempt anaphor as grammatical, we expect B to be available as the answer, since strict readings should become available in exempt binding contexts and speakers who allow the strict reading may find it to be most salient one for the given context. ${ }^{14}$

(19) Heera ${ }_{i}-$ nun [tongchanghoy ${ }_{j}-k a \quad\left[\right.$ caki-casin $_{i}-\mathbf{i}$ taumcwu-ey kyelhonhana-nun

Heera-top alumni.assoc-nom self-nom next week get-married-rel

sasil]-ul imi palphyohayssta]-ko malhayssta.-

fact-acc already announced-comp said

'Heera said that the alumni association already announced the fact that she (self) would get married next week.'

Ungrammatical

1
2
3
Grammatical

5

\footnotetext{
${ }^{13}$ Conflicting PIVOTs are also invoked as the basis for the discourse conditions underlying the Blocking Effect in Cole et al. (2006). They note that the conflict results in degradedness, but not complete unacceptability (the acceptability marking is theirs).

(i) a. Zhangsan ${ }_{i}$ zhidao [Mali gen ziji ?? shuoguo [ni xiang qu Taiwan ]] (=68 in Cole et. al.)

ZS knows $M$ with self said you want go Taiwan

'Zhangsan knows that Mary told self(=ZS) that you want to go to Taiwan.'

b. Zhangsan ${ }_{\mathrm{i}}$ zhidao [Mali gen $\mathrm{ziji}_{\mathrm{i}}$ shuoguo [Lisi xiang qu Taiwan]]

ZS knows $M$ with self said LS want go Taiwan

'Zhangsan knows that Mary told self(=ZS) that Lisi wants to go to Taiwan.'

Cole et al. suggest that the reason a non-intervening first or second person NP (=the most embedded subject in ia,b above) results in the reduced acceptability of anaphor binding is that such NPs indicate an external PIVOT and interferes with the binding of long-distance ziji by an internal PIVOT (=the matrix subject).

What is important for our purposes is that such conflicts do not result in a sharp judgment of unacceptability. That is, even though there is a conflict in PIVOT choice in (ia), it must be possible for speakers to overcome the conflict to obtain the requisite binding. However, since doing so involves additional computation (=resolving the conflict in PIVOT choice in parsing the sentence), there seems to be a cost, which is reflected in the lessened degree of acceptability.

The sentences we categorized as Less Logophoric have the same property. Thus, we do not expect speakers to judge them to be completely unacceptable, but to assign them a lower degree of acceptability. As we shall see, our experimental results confirm this expectation.

${ }^{14}$ The question arises why we asked subjects to choose only one (i.e., the most salient) interpretation. If a subject chooses B (strict reading), we can be confident that for such speakers the strict reading is not only available but is the dominant reading in the given context. However, even if a subject chose A (sloppy reading), it is possible that the strict reading is also available to that speaker, though it may not be the dominant reading. In this sense, our measure of strict readings was conservative. Nonetheless, we obtained a significant percentage of dominant strict readings to allow us to conclude that the anaphors in question are exempt anaphors.
} 
Aera-to kulekey malhay-ss-ta ${ }^{15}$

Aera-too so

say-past-decl.

'Aera said so too.'

Interpretation:

A. Aera-nun [tongchanghoy-ka Aera-ka taumcwu-ey kyelhonhanta-nun sasil-lul imi palpyohayss-ta-ko] malhay-ss-ta.

(= Aera said that the alumni association already announced that Aera would get married.)

B. Aera-nun [tongchanghoy-ka Heera-ka taumcwu-ey kyelhonhanta-nun sasil-lul imi

palpyohayss-ta-ko] malhay-ss-ta.

(= Aera said that the alumni association already announced that Heera would get married.)

C. Neither of the above is a possible interpretation of the sentence.

The ungrammatical distractor items were composed of sentences of similar length to the target items. An example of an ungrammatical distractor item is (20). (20) is ungrammatical due to the case-marking of two NPs (cha 'car' and Chelswu). To make this sentence grammatical, we have to change the case-marking of $c h a$ 'car' from nominative (-ka) to accusative (-lul), which will give us the interpretation 'his car told Chelswu not to take it, because the gas price is too high.' Without the right case-markers, the sentence in (20) is impossible to interpret.
*Kilumkaps-i
pissacinta-nun iywu-lo
[caki-casin-uy
cha-ka Chelswu-ka
Gas.price-nom
increase-rel reason-for self-poss
car-nom Chelswu-nom
kaciko tanici mala]-ko tangpwuhay-ss-ta
carry go not-comp ask-past-decl
Intended: '*Because the gas price increased, self's car asked Chelswu not to drive it.'

Since sentence like (20) do not have an appropriate interpretation, in addition to judging it as ungrammatical, speakers are expected to select $\mathrm{C}$ for its interpretation, as ungrammatical sentences do not have an interpretation. This type of ungrammatical sentence serves as a reference point for 'ungrammatical' in the given grammaticality scale.

\subsubsection{Procedure}

Participants were first asked to fill out a simple one-page questionnaire survey about biographical information such as age, gender and dialect(s) of Korean they use. They were then asked to read the instructions for the main task and proceed to the task. In the main task, participants were required to judge the degree of grammaticality of a given sentence in a 5-point Likert scale and then to choose an appropriate interpretation of an immediately following (underlined) sentence containing VP-ellipsis/proform.

However, based on the performance on the Preferential Sentence Interpretation task, responses that were not reliable and might confound the pattern of the results were screened. For example, if subjects judged the test sentence as ungrammatical, their responses on the following sentences with VP-ellipsis/proform cannot be considered reliable unless they choose response $\mathrm{C}$ (='Neither of the above is a possible interpretation.'). This is because an ungrammatical sentence cannot have an interpretation. Therefore, responses which judged the sentences as ungrammatical but nevertheless chose A or B readings were set aside in the statistical analysis of judgments on strict/sloppy readings (6\% of the responses were dropped by this procedure).

Also, responses which rated the sentences as grammatical (giving a score higher than 3) but chose C for interpretation were dropped, as these responses cannot be considered to be reliable ( $1 \%$ of the responses was dropped

\footnotetext{
${ }^{15}$ The items we used to test for strict vs. sloppy readings in VP-ellipsis/proform actually do not involve ellipsis, but instead possess the pro-form kulehkey (equivalent of 'so' in 'do so' in English) which replaces the entire embedded clause containing the anaphor. Therefore, technically, the test in question is a VP proform test. We do not think the results are jeopardized by this test, since the strict/sloppy interpretations are also found in VP proform contexts as in VP ellipsis contexts, as we see below:

(i) John really hates himself. Bill does so, too (sloppy $>*$ ?strict)

(ii) John thinks that an article about himself appeared in the Times. Bill does so/thinks so, too (strict > ??sloppy)

Whether VP ellipsis as such exists in Korean and if so, what constructions exemplify it has been the subject of much debate (Otani and Whitman, 1991; Kim, 1999, among others). The strict/sloppy ambiguity is not an exclusive property of VP ellipsis, but attested more generally (Kim, 1999). Therefore, the fact that we use VP proforms should not affect the point we make in this paper.
} 
by this procedure). ${ }^{16}$ On the other hand, responses which assigned a low grammaticality score (1 or 2) for the target sentence and chose $\mathrm{C}$ for interpretation were considered for the analysis, since these are valid responses that fall into the category of 'not accepting LD binding' even when pragmatically plausible contexts are provided.

\subsubsection{Analysis}

The grammaticality score for each sentence was calculated with mean score and standard deviation across subjects. From the 5-point Likert scale, the grammatical points given by the subjects were interpreted according to the following criteria [1: incorrect, 2: maybe incorrect, 3: I don't know, 4: maybe correct, 5: correct]. Scale 3 is interpreted as 'not sure about grammaticality', while 4-5 are interpreted 'grammatical' and 1-2 as 'ungrammatical'. ${ }^{17}$

The responses were then grouped according to sentence types (by logophoric roles of antecedents-SOURCE, SELF, PIVOT; by logophoric vs. less logophoric antecedents; by TSC violation vs. TSC and SSC violation) and averaged by sentence types. Repeated Measures Analysis of Variance (ANOVA) and Paired Sample T-test were run to determine the statistical significance of the differences for distinct within-subject factors.

\subsection{Results}

Overall results from the experiment were as follows:

i) Sentences representing LD exempt binding and those containing core binding attained very similar grammaticality scores (Exempt binding: mean $=4.17$; Core binding: mean $=4.21$ ). However, the distractors garnered a much lower grammaticality score (mean $=1.99$ ) compared to the target sentences containing core and exempt binding.

ii) The responses categorized by the logophoric roles of antecedents revealed that sentences containing SOURCE antecedents attained the highest grammaticality scores. Those with SELF antecedents attained scores lower than SOURCE but higher than PIVOT. Sentences containing Less Logophoric antecedents attained lower overall grammaticality scores than those with clear logophoric antecedents, but higher than the distractors.

A repeated measures ANOVA conducted with sentence type as a within-participants variable with 12 levels revealed that sentence type was significant $[F(11,451)=66.455 ; p<.000]$. The pattern of the results for distinct sentence types is shown in Table 1.

First, subjects accepted long-distance exempt binding of caki-casin very robustly when appropriate logophoric conditions were given. ${ }^{18}$ The degree of grammaticality for sentences with LD bound caki-casin (with both TSC and SSC violations) did not differ significantly from those with core bound caki-casin (TSC-only violation) (TSC only: mean $=4.21$, S.D. $=0.77$; TSC and SSC: mean $=4.17$, S.D. $=0.45$ ). The mean grammaticality score of the distractors $($ mean $=1.99$, S.D. $=0.76)$, however, differs significantly from the two sentence types. The pattern of the results with different types of binding is shown in Fig. 1.

A repeated measures ANOVA conducted with binding type as a within-participants variable with 2 levels (core binding, exempt binding) showed that the binding type was not significant $\left[F(1,42)=.023, p<.881\right.$, ns.]. ${ }^{19}$

Second, participants assigned significantly higher grammaticality scores for sentences with clearly identifiable logophoric antecedents (SOURCE: mean $=4.44$, S.D. $=0.43 ;$ SELF: mean $=4.19$, S.D. $=0.54 ;$ PIVOT: mean $=3.80$, S.D. $=0.72$ ) than those where such identification was difficult, the Less Logophoric cases (i.e., where external and

\footnotetext{
${ }^{16}$ Subjects who responded this way might have chosen local binding, even when the local antecedent does not match the anaphor in features, and might have based their high grammaticality ratings upon the local binding interpretation. When they turned to the interpretation task, they failed to find the local construal and hence chose $\mathrm{C}$. If this is what they were doing, their responses cannot be considered in judging the acceptability of longdistance exempt binding.

${ }^{17}$ Some studies use grammaticality scales that range from -2 to +2 , in which 0 indicates 'not sure about grammaticality', where scores below zero are considered 'ungrammatical' and those above zero 'grammatical'. The 5-point scale that we used in this study is similar, in that 3 indicates the same degree of relative grammaticality as 0 . Therefore, in this study, the mean scores above 3 are regarded as 'grammatical' responses while those below 3 are considered to be 'ungrammatical' responses.

${ }^{18}$ A reviewer asks how we can explain the relative low acceptability score with long-distance PIVOT antecedents. The reason must be that among the logophoric centers, PIVOT is the least canonical (Sells, 1987).

${ }^{19}$ As noted earlier, we will revisit the question of whether TSC-violating caki-casin is indeed a core anaphor in section 3.4.
} 
Table 1

Grammaticality scores by sentence types.

\begin{tabular}{lll}
\hline & Binding type & Logophoric role \\
\hline Mean (S.D.) & Core binding (TSC violation): 4.21 (0.77) & N/A \\
& Exempt binding (TSC and SSC violation): 4.17 (0.45) & SOURCE: 4.44 (0.43) \\
& & SELF: 4.19 $(0.54)$ \\
& PIVOT: 3.80 $(0.72)$ & LESS LOGOPHORIC: $\mathbf{3 . 4 3}(0.84)$ \\
& Ungrammatical distractors: $* \mathbf{1 . 9 9}(0.76)$ & N/A
\end{tabular}

*epresents that the number is statistically significant.

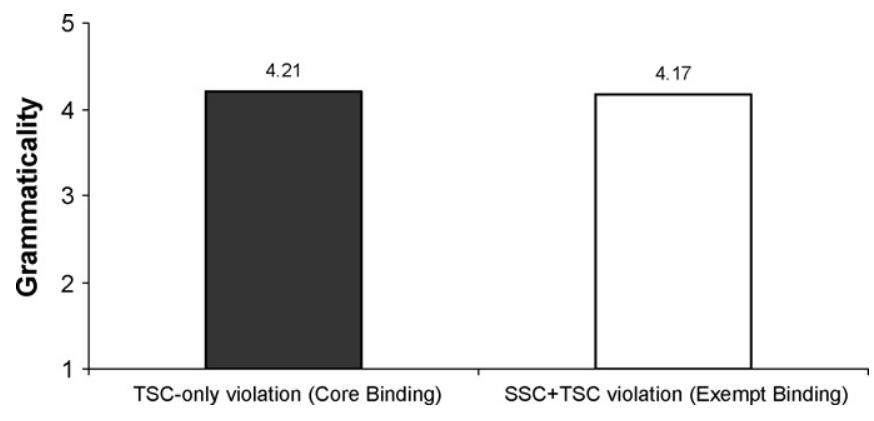

Fig. 1. Grammaticality of core vs. exempt binding.

internal logophoric centers were in conflict, or where Point of View/PIVOT shift was necessary within a sentence-as in (18)) (mean = 3.43, S.D. = 0.84). The pattern of the results with different logophoric roles is shown in Fig. 2.

A repeated measures ANOVA conducted with logophoric role as a within-participants variable with 4 levels showed that logophoric role was significant $[F(3,126)=42.257, p<.000]$. The Paired Sample $T$-test showed that the grammaticality score of sentences with SOURCE antecedents was significantly higher than those with SELF antecedents $[t(42)=4.315, p<.000]$, as well as those with PIVOT $[t(42)=6.627, p<.000]$. In turn, the sentences with SELF antecedents attained significantly higher grammaticality scores than those with PIVOT antecedents $[t(42)=4.332, p<.000]$ and those with Less Logophoric antecedents $[t(42)=8.376, p<.000]$. The grammaticality score of the sentences with PIVOT antecedents was significantly higher than that of the sentences with Less Logophoric antecedents $[t(42)=2.701, p<.010]$. Therefore, the results of the grammaticality rating of sentences according to the different logophoric roles of the LD antecedent are consistent with the hierarchy of logophoric roles as proposed in Sells (1987)—SOURCE $>$ SELF $>$ PIVOT.

Third, in the Preferential Sentence Interpretation Task, the strict reading was chosen as the dominant reading by most participants in the case of long-distance bound exempt caki-casin. The strict reading was chosen as the dominant reading by $50 \%$ of the subjects, while $27 \%$ chose the sloppy reading as the dominant reading. However, what was intriguing was that the participants chose the strict reading as the dominant reading over the sloppy reading even in the case of core binding (Rate: sloppy reading $=31 \%$; strict reading $=49 \%$; neither reading $=7 \%$; no response $=13 \%$ ).

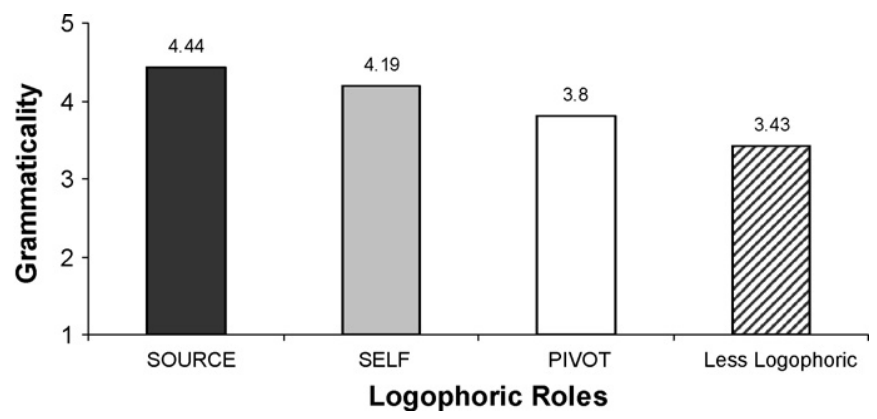

Fig. 2. Grammaticality score of exempt binding by logophoric roles of antecedents. 


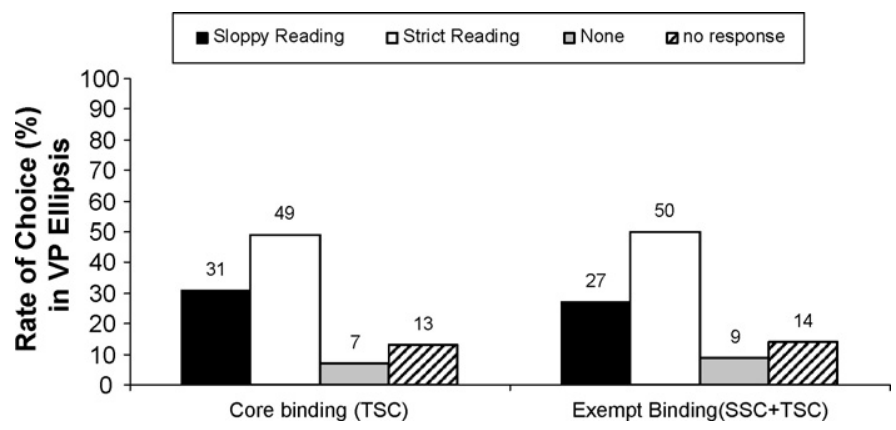

Fig. 3. Choice of dominant reading in VP-ellipsis/proform contexts.

Therefore, the difference between core binding and exempt binding in their choice of dominant readings was not significant. Overall results are shown in Fig. 3.

The choice of the dominant reading broken down by logophoric roles of antecedents is as follows: SOURCE antecedents got the highest rate of dominant strict reading (62\%); SELF was the second highest (60\%), followed by PIVOT (20\%).

This pattern of the result is shown in Fig. 4.

What is interesting in these results is that in sentences containing long-distance PIVOT antecedents (i.e., those with directional auxiliary $o$-ta 'come') and in those with Less Logophoric antecedents (i.e., those with the directional auxiliary ka-ta 'go', which requires a POV shift between the adjunct and the main clause), the sloppy reading was chosen as the dominant reading more frequently than the strict reading (PIVOT antecedent: strict-20\% < sloppy-41\%; Less Logophoric antecedent: strict-28\% < sloppy-32\%).

\subsection{Discussion}

\subsubsection{Interpretation of overall results}

The summary of the experimental results given earlier is as follows:

i) Korean native speakers judged sentences with LD binding of the local anaphor caki-casin as grammatical overall when an appropriate logophoric context was given.

ii) Regarding the logophoric roles of antecedents of LD-bound/exempt caki-casin, sentences with SOURCE antecedents were assigned the highest grammaticality scores, while those where the antecedent was PIVOT got the lowest grammaticality scores. Sentences with clearly identifiable logophoric antecedents (SOURCE, SELF, PIVOT) as a group obtained higher grammaticality scores than those where the determination of logophoric antecedents was difficult, i.e., the Less Logophoric sentence types where POV shift between the adjunct clause and the matrix clause was required, or where a conflict arose between distinct logophoric roles.

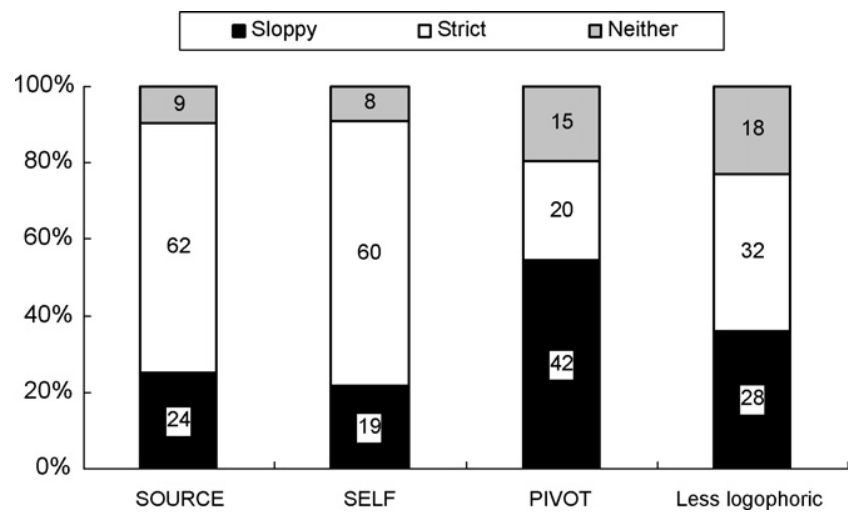

Fig. 4. Choice of dominant readings by logophoric roles of antecedents. 
iii) In contexts of VP-ellipsis/proform, speakers chose the strict interpretation of caki-casin as the dominant reading in the case of LD exempt binding. However, even in contexts of sentences that only violate TSC (core binding), the strict reading was chosen as the dominant reading by a majority of speakers.

Our interpretation of these results is as follows.

We take result i) to support the first prediction of our hypothesis, that sentences with LD bound caki-casin would be judged grammatical by native speakers of Korean.

Result ii) in turn supports the second prediction, which was that there would be differences in grammaticality according to the different logophoric roles of LD antecedents of caki-casin. Furthermore, the pattern of obtained results is consistent with the hierarchy of logophoric roles proposed in Sells (1987).

However, while the overall results seem to support the second prediction, there was individual variation among subjects. The majority of speakers (31 out of 43) differentiated sentences according to the logophoric roles of antecedents and assigned scores that matched Sells' (1987) canonical hierarchy of logophoric roles. But a closer look at individual results revealed that around $28 \%(n=12$ out of 43$)$ of the tested subjects did not discriminate among sentences containing different logophoric roles. These subjects either assigned a score of 4 point or higher to all the target items or did not follow the canonical hierarchy (SOURCE $>$ SELF $>$ PIVOT $>$ Less Logophoric antecedents) consistently in their responses.

Also, even among the speakers who showed responses in line with the hierarchy of logophoric roles, $19 \%$ ( $n=6$ out of 31) did not consistently distinguish sentences with PIVOT antecedents from those with Less Logophoric antecedents, either by giving very similar scores to both types of sentences, or by giving higher scores to sentences with Less Logophoric antecedents than those with PIVOT antecedents. These speakers appear to be flexible with POV shift, which may have allowed them treat the two types of sentences similarly.

Result iii) of the present study might be taken to imply that majority of the participants who accept LD binding of caki-casin also treat it as an exempt anaphor. However, the fact that TSC-violating core anaphors also showed a high proportion of strict readings prevents us from drawing the conclusion that our third prediction is supported.

As noted, for core binding, the expected pattern of sloppy reading dominance was not found in that the responses choosing the sloppy reading as the dominant reading did not outnumber those choosing the strict reading. ${ }^{20}$ In fact, if the sentences we took to exemplify core binding (i.e., sentences violating only TSC) were indeed instances of core binding, we should not be able to obtain strict readings in any measurable degree in the first place.

A possible interpretation of this state of affairs is that sentences containing TSC-violating caki-casin do not in fact exemplify core binding but exempt binding instead, contrary to the assumptions we made. This interpretation gains plausibility when we take the following into consideration.

First, even though we did not test the relevant judgments experimentally, since we could not foresee the pattern of responses by the subjects and were proceeding on the basis of the common assumption in the literature that all anaphors, including local anaphors, can violate TSC in languages like Korean, what we find is that when caki-casin has a clause-mate antecedent, it is, or can only be, interpreted sloppily. ${ }^{21}$

(21) John-i iywu epsi caki-casin-ul miwehanta-ko (na-nun tul-ess-ta)

J-nom reason without self-acc hate-comp (I-top hear-pst-decl)

'(I heard that) John hates self without reason.'

Kulentey yocum Bill-to kulenta-tela

By.the.way these.days B-also do.so-I.hear

'I heard that these days Bill does so, too.'

$\rightarrow$ (I heard) Bill hates Bill; *(I heard) Bill hates John

\footnotetext{
${ }^{20}$ And given that we asked subjects to choose the dominant reading only, the choice of the sloppy reading as dominant does not guarantee that the strict reading is unavailable to the subjects who made such a choice.

${ }^{21}$ The relevance of these sentences to the overall argument was pointed out by an anonymous reviewer, who suggested that a supplemental experiment be run to obtain the dominant readings with these types of sentences. While the point is well taken, we do not believe that an experimental study is necessary to prove the point that caki-casin with local antecedents only allows the sloppy reading, as the judgments are quite robust and uniform.
} 
This tells us that there is indeed an expected sloppy reading dominance in at least the clause-mate bound instances of caki-casin, so that the availability of the strict reading (as the dominant reading, to boot) in sentences containing TSC-violating caki-casin is not due to the lexical property of the anaphor which allows both strict and sloppy readings regardless of the type of binding involved. ${ }^{22}$

A second reason to suppose that TSC-violating caki-casin may not be a core anaphor is the contrast between cakicasin and other LDAs (e.g., caki, casin) in the same environments. The following contrasts are suggestive. ${ }^{23,24}$

a. Cheli-nun caki-ka/casin-i chencayla-ko sayngkakhanu-nkes kathta

C-top self-nom genius-comp think-comp seems

'Cheli seems to think that self is a genius.'

Tongswu-to kule-nkes kathta/kulehkey sayngkakhanu-nkes kathta

T-also so-comp seems/so think-comp seems

'So does Tongswu/Tongswu seems to think so, too.'

$\rightarrow$ Tongswu thinks Tongswu/*? Cheli is a genius

b. Cheli-nun caki-casin-i chencayla-ko sayngkakhanu-nkes kathta

C-top self-nom genius-comp think-comp seems

'Cheli seems to think that self is a genius.'

Tongswu-to kule-nkes kathta/kulehkey sayngkakhanu-nkes kathta

T-also so-comp seems/so think-comp seems

'So does Tongswu/Tongswu seems to think so, too.'

$\rightarrow$ Tongswu thinks Tongswu/Cheli is a genius

(22b) replicates the type of sentences in our experimental data for which speakers chose the strict reading as the dominant reading, though we predicted that strict readings should not be available since we took the sentences to exemplify core binding. (22a) is parallel to (22b) but contain caki or casin instead of caki-casin. Even though the judgments we report here must be confirmed experimentally, we feel that the strict interpretation of the anaphor becomes much more difficult in (22a), when compared to (22b) (or the sentences we used in the experiment that are similar in design which allowed strict readings).

A possible reason for the differences observed above might be that caki and casin in Korean are bound anaphor type genuine LDAs (in the typology of LDAs in Cole et al., 2001, 2006) in TSC-violating contexts while caki-casin may actually be an exempt anaphor even in this context, contrary to what we assumed as we were designing the experiment. This may explain why caki-casin with clause-mate antecedents only allows sloppy readings while TSC-violating cakicasin, unlike caki and casin in similar contexts, allows both strict and sloppy readings.

Finally, if TSC-violating caki-casin is an exempt anaphor, as we are suggesting, we can also make sense of why the grammaticality rating of sentences with TSC-violating caki-casin was not close to perfect, with a fair amount of individual variation $(4.21$, S.D. $=0.77)$. If these sentences exemplify exempt binding, discourse factors would still

\footnotetext{
${ }^{22}$ If caki-casin allowed both sloppy and strict readings even in clause-mate binding, it would be an example of a form that is neutral between reflexive and pronoun (like the Malay dirinya) in the typology of LDAs given in Cole et al. $(2001,2006)$. The fact that it doesn't indicates that it is a true reflexive, as we have been assuming all along.

${ }^{23}$ Again, we are not basing our claim on experimental data. The importance of comparing the behavior of caki-casin with other (genuine) LDAs in the language was pointed out by an anonymous reviewer, who suggested that the relevant data should be presented, even if they are nonexperimental. It also seems to us that there is a further difference between caki and casin in this regard. While strict readings can be forced with caki, casin does not allow strict readings at all. Obviously, these intuitions need to be tested with further experimental work.

${ }^{24}$ Another test of bound variable readings ('only NPs'), combined with the ellipsis/proform test, yields a similar array of judgments, for speakers we have consulted.

(i) Cheli-man casin-i/caki-ka/cakicasin-i chencayla-ko saynkakhanta

C-only self-nom genius-comp thinks

'Only Cheli thinks that self is a genius.'

Tongswu-nun an-kulenta/kulehkey sangkakha-ci anhnunta

T-top neg-do.so/so think-comp neg

'Tongswu doesn't/Tongswu doesn't think so.'
}

The strict reading ('Tongswu doesn't think that Cheli is a genius.') is unavailable with casin (and caki), but becomes easier to obtain with cakicasin. 
figure in the computation of acceptability. In other words, if speakers fail to posit the relevant discourse conditions, they would judge the sentences as less than fully acceptable.

If the above line of explanation is on the right track, we predict that other local anaphors should behave similarly to caki-casin in TSC-violating contexts. That is, they should be licensed as exempt anaphors, be subject to discourse conditions and should allow both strict and sloppy readings in contexts of proforms and ellipsis. As far as we know, the possibility that some anaphors in Korean may not violate TSC as a constraint on core binding has never been explored previously. This is because (almost) all anaphors-whether simple or complex-can occur as embedded subjects of finite clauses, violating the TSC. And yet, simple acceptability of a given anaphor is no guarantee that it is licensed by grammatical binding, according to the best current understanding. What we are suggesting through the reinterpretation of TSC-violating caki-casin is that when local anaphors such as caki-casin occur in sentences with TSC violations, they do so only if they can be licensed as an exempt anaphor, but never as a core anaphor. This is an intriguing possibility to which we were led by the results of the experimental evidence. ${ }^{25}$

In sum, if TSC-violating caki-casin is an exempt anaphor, we can understand why it allows both sloppy and strict readings. But then why should the strict reading be chosen as the dominant reading by a majority of speakers?

One possible explanation is as follows. Compared to the other anaphors, caki-casin is emphatic. ${ }^{26}$ Emphasis might have played a role in leading speakers to favor the strict reading over the sloppy reading. The role of emphasis in facilitating the strict reading is shown in (23). In (23a), both the sloppy reading (i.e., Bill hates Bill's brother) and the strict reading (i.e., Bill hates John's brother) are possible for the pronoun. However, in (23b), the elliptical VP is interpreted as 'Bill hates even/only John's brother (strict reading)' and the sloppy interpretation is not natural in this context.

a. John hates his brother. Bill does (so), too.

b. John hates even/only his brother. Bill does (so), too.

It seems that focus on 'his brother' is blocking the sloppy reading. If this is the case, we may have one possible explanation as to why speakers chose the strict reading as the dominant reading in sentences where caki-casin violates the TSC.

We also noted that while the strict reading was chosen as the dominant reading with exempt anaphors bound by SOURCE and SELF antecedents, the sloppy reading was chosen as the dominant reading in the case of PIVOT and

\footnotetext{
${ }^{25}$ In this respect it is interesting to note that susulo ('on one's own'), which is an adverbial/adnominal/nominal anaphor, is strictly locally bound. It can violate neither SSC nor TSC, as shown below:

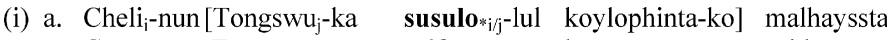

C-top T-nom self-acc harass-comp said

'Cheli said that Tongswu is harassing self(=Tongswu, *Cheli).'

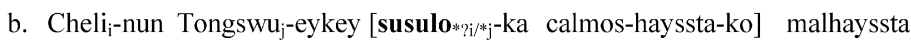

C-top T-dat self-nom wrong-did-comp said

'Cheli told Tongswu that self(=*?Cheli, *Tongswu) made a mistake.'

This may be because while susulo is a local anaphor like caki-casin, it is less amenable to conversion into an exempt (pronominal) anaphor, because unlike caki-casin, there is no pronoun-like (i.e., Det-like) element associated with susulo that can function pronominally.

The local anaphor pronoun-casin is similar to caki-casin. In clause-mate binding, it only allows the sloppy reading, while in TSC-violating contexts, the strict reading seems possible.

(ii) Cheli-nun ku-casin-ul iywu epsi haktayhanta

C-top he-self-acc reason without tortures

'Cheli is harsh on himself for no reason.'

Tongswu-to yocum kulenta

T-also recently do.so

'So is Tongswu these days.' $\rightarrow$ Tongswu is harsh on Tongswu/*Cheli

(iii) Cheli-ka chinkwutul-eykey [ku-casin-i ku il-ey cekimca-la-ko] malhay-ss-ta

C-nom friends-dat he-self-nom that job-loc best-cop-comp say-pst-decl

'Cheli told his friends that self is the best person for that job.'

Tongswu-to kulayssta/kulehkey malhay-ss-ta-(ko tulessta)

T-also said.so/so say-pst-decl(-comp I.heard)

'I heard Tongswu/Tongswu said so, too.' $\rightarrow$ Tongswu said Tongswu/Cheli is the best person for that job.

${ }^{26}$ This was pointed out to us by Susumu Kuno.
} 
Less Logophoric antecedents. The fact that both strict and sloppy readings are available is predicted by our hypothesis since we take the anaphors to be exempt anaphors. What needs to be explained is why in the case of less canonical logophoric antecedents (PIVOT and Less Logophoric antecedents) speakers chose the sloppy reading as the dominant reading.

When we examined the test items, we discovered that an explanation of this pattern of response could be found in the fact that the target items for PIVOT antecedents were biased in favor of the sloppy reading. The problem is illustrated below.

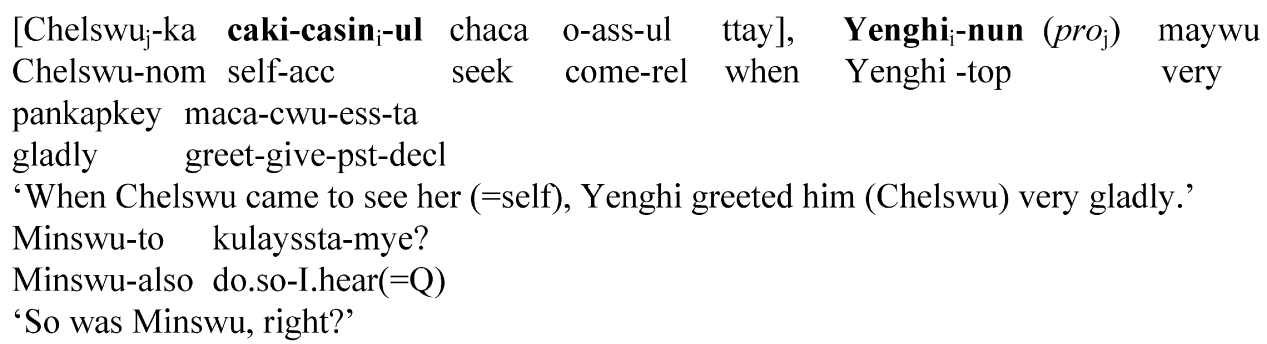

\section{Neither}

In (24), the strict reading shown in B poses a problem in terms of the consistency of POV. This is because the auxiliary $o$-ta ' $\mathrm{go}$ ' in the adjunct clause points to Yenghi as the deictic center, but when the matrix predicate is encountered, the subject, which is the antecedent of the anaphor, denotes a different person, Minswu. The sloppy reading in A poses no such conflict in POV, and hence, it may have been preferred by speakers.

If this explanation is valid, we expect that in sentences containing Less Logophoric antecedents with the auxiliary $k a-t a$ 'go' instead of $o$ - $t a$ 'come', the strict reading (interpretation shown in B as above) would be easier to obtain, since it does not necessitate a POV shift. This was in fact the case. Sentences with Less Logophoric antecedents yielded more strict readings compared to those with PIVOT antecedents (Mean rate of strict reading: PIVOT antecedent, 20\%, Less Logophoric antecedent, 32\%). This supports our explanation that a design bias is what led to the higher rate of sloppy readings with PIVOT antecedents. If not for the bias, we may not have obtained a high proportion of sloppy readings with PIVOT antecedents.

However, it is important to emphasize that the exempt anaphor hypothesis predicts simply that both strict and sloppy readings should be available, and not that the strict reading should be more dominant than the sloppy reading, so that the responses to these sentences do not falsify the predictions of our hypothesis. Nevertheless, we were able to identify the factors that may have contributed to the choice of one reading as the dominant reading.

To summarize, on the face of it, result iii) does not support the third prediction of our hypothesis, because core binding yielded a high proportion of strict readings, contrary to expectations. However, we suggested that it may be because the TSC-violating sentences that contain caki-casin instantiate exempt rather than core binding. We reached this conclusion on the basis of two considerations. One, for unambiguous cases of core-bound caki-casin (i.e., when it occurs with clause-mate antecedents), only the sloppy reading is available. Secondly, caki-casin contrasts with other genuine, bound anaphor-type LDAs (caki, casin) in TSC-violating contexts in that the latter do not easily admit strict interpretations while caki-casin does. 
If this reinterpretation is on the right track, we do have evidence that supports the third prediction of our hypothesis, though the evidence does not come exclusively from the data that we tested in our original experiment.

In the next two sections, we turn to two issues that are relevant to the overall investigation of exempt binding but were not identified as primary research questions in our work. The first has to do with the question of whether core and exempt binding are in complementary distribution as assumed by Pollard and Sag (1992) and Huang and Liu (2001), or may be in an overlapping distribution (Pollard and Xue, 2001; Runner et al., 2002, 2006). The second has to do with whether structural prominence can facilitate the identification of logophoric antecedents in LD exempt binding.

\subsubsection{Domain for core vs. exempt binding}

An interesting result of our study comes from non-target items containing multiple potential antecedents. As stated earlier, the analysis of sentences containing multiple potential antecedents was done separately from the other target sentences with LD exempt binding; therefore, the responses to these items were not considered in the analysis of LD exempt binding discussed so far. An example is shown in (25).

In (25), caki-casin can be bound by more than one potential antecedent. Being animate and 3rd person, all three NPs (Hyori, Ceytong and Cenghyen) can serve as potential antecedents of caki-casin in this sentence. They also function as logophoric centers. Hyori is a SOURCE while Ceytong can be treated as a PIVOT in the right discourse context. Cenghyeni is an Experiencer, hence, a SELF.

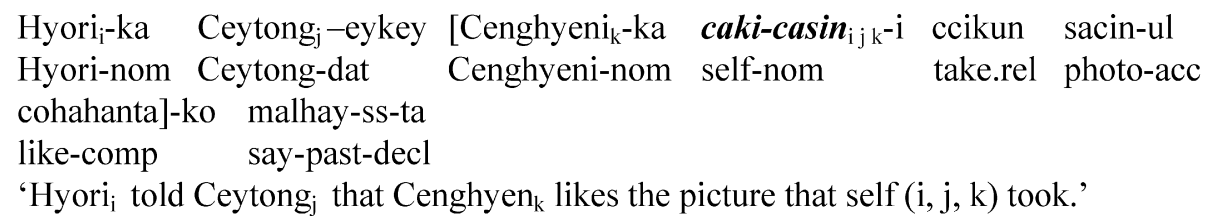

This type of sentence was designed to test the possibility of long-distance binding of caki-casin when there are multiple potential antecedents-both local and long-distance. Judgments on these sentences can tell us if speakers get LD construals of caki-casin even when there is a potential (i.e., Person-feature matched, c-commanding) antecedent that is more local. That is, this type of sentence allows us to ascertain answers to questions about the nature of exempt binding. If caki-casin is licensed as an exempt anaphor only when local antecedents are unavailable-in other words, if exempt binding is found only in contexts where core binding fails as assumed in Pollard and Sag (1992) and Huang and Liu (2001)—subjects should show a strong preference for local binding (i.e., Cenghyeni) in this sentence type. However, if core and exempt binding are not in complementary distribution (Pollard and Xue, 2001; Iida, 1992; Runner et al., 2002, 2006), subjects might still accept long-distance binding.

Except for 5 out of 43 individuals, the tested subjects judged this type of sentence to be grammatical. However, a higher grammaticality rating for this type of sentence does not necessarily imply that the subjects are accepting the LD construal of caki-casin. This is so because subjects could have given a higher grammaticality rating based on the local construal of the anaphor. We therefore need to examine the performance on the interpretation task to determine what speakers are doing. $71 \%$ of the responses that rated the sentences as grammatical chose A or B as the dominant reading. ${ }^{27}$ The readings indicated as A and B (sloppy and strict readings) reflect long-distance construals of the anaphor. Therefore, the subjects who responded this way can be taken to have accepted the LD-binding of caki-casin. By contrast, if a subject gave a high grammaticality score to the test sentence but chose $\mathrm{C}$, the grammaticality ratings were likely based on the local construal of the anaphor. $23 \%$ of the responses that rated this type of sentence as grammatical patterned this way. ${ }^{28}$

Even though there were speakers who did not accept LD-binding with this sentence type, the fact that the majority of subjects treated this sentence type as grammatical and chose long-distance construals (A or B) as the dominant reading implies that caki-casin can still be LD-bound as an exempt anaphor in such contexts for many speakers.

Before we can draw a firm conclusion, however, we need to rule out an alternative explanation based on structural priming. Since subjects were directed to seek the LD antecedent in the other target sentences, their responses to these sentences might simply reflect a bias in the subjects' processing, combined with the specific interpretation (i.e., caki-

\footnotetext{
$2749 \%$ of the responses that judged the items are grammatical chose the strict reading as the dominant reading while $15 \%$ chose the sloppy reading as dominant.

${ }^{28}$ We discarded the responses which rated these sentences as ungrammatical but chose A or B, since these responses can not be considered reliable, given that ungrammatical sentences do not have an interpretation ( $6 \%$ of the responses were dropped for this reason).
} 
casin bound by a LD antecedent) profiled from the context. However, a previous study with Korean-English bilinguals Kim and Montrul (2004) obtained a similar pattern of result. Korean monolingual speakers accepted the LD binding of caki-casin in about $25 \%$ of their responses when they were given contextual information with pictures. In that study, there was no structural priming for long-distance binding since felicitous antecedents included local as well as longdistance antecedents.

Therefore, what the result of this study and that of Kim and Montrul (2004) may imply is that the local anaphor caki-casin can be LD-bound even in the presence of local antecedents as long as appropriate contextual information is available. The contribution of context in facilitating LD binding of local anaphors was found even for English (Lee, 2007; Runner et al., 2002), so that the result we obtained with this type of sentence is not surprising. The position defended by Pollard and Xue (2001), Iida (1992), and Runner et al. (2002), Goldwater and Runner (2006), which takes core and exempt anaphors to overlap in their distributions, is supported by the behavior of caki-casin in Korean.

While the above interpretation is plausible, there still remains the fact that a significant discrepancy exists between results of previous research and the results obtained in our study. The discrepancy lies in the fact that the vast majority of subjects we tested preferred LD binding (71\%) while a minority (around 25\%) chose the LD construal in previous studies. How can we explain the discrepancy? Does this mean that contrary to what had been claimed earlier, cakicasin is in fact a long-distance anaphor like caki and casin?

Once we scrutinize the test items, we find that there is a way of make sense of the results. In using items like (25) to test the question of the possible overlap of domains of local/core and LD/exempt binding, we were again operating under the assumption that TSC-violating caki-casin in Korean behaves as a core anaphor when it is bound by an antecedent in the next clause up. Recall, however, that in order to make sense of the high percentage of strict readings by subjects on TSC-violating 'core binding' sentences, we suggested that TSC-violating caki-casin might in fact be an exempt anaphor.

If this interpretation is on the right track, all the potential antecedents of caki-casin in (25) - including the most local antecedent - are LD antecedents that need to be licensed through exempt binding. In that case, the local antecedent will not be privileged over the non-local antecedents, contrary to what we had expected. In fact, the most non-local one will, if anything, be privileged over the others given its prominence. This may explain why the closest potential antecedent was not chosen as the actual antecedent by the subjects. By contrast, the test items in Kim and Montrul (2004) had an embedded clause-mate subject as the local antecedent of an anaphor in object position, with non-local antecedents outside the minimal clause where the anaphor was embedded. Thus, the local antecedent was accessible through core binding, while non-local antecedents had to be sanctioned by exempt binding. As noted, speakers still were able to obtain long-distance construal in such cases, but not as the dominant construal of the anaphor.

The results interpreted this way support the suggestion we made earlier that local anaphors like caki-casin may not be able to violate TSC in core binding and that when they do appear in such contexts, they do so as exempt anaphors. Thus, the domain for core binding for local anaphors in languages like Korean is identical to that for local anaphors in languages like English, being defined by both TSC and SSC, contrary to what had been assumed. This is an interesting conclusion that demands verification by further experimental results. The possibility that the domains of core and exempt binding may overlap is still open (as the results of Kim and Montrul, 2004 and the studied cited above indicate), but we cannot establish that using data such as (25).

\subsubsection{Exempt binding and structural prominence}

Another question we considered was the following: Do grammatical-structural factors (subject vs. non-subject antecedents; c-commanding vs. non-c-commanding antecedents) affect the acceptability of the long-distance binding of caki-casin? The rationale for this question is the following: while exempt anaphors are judged not to be constrained by structural factors such as grammatical relation and structural c-command, it is possible that those factors might have effect determining the well-formedness of exempt binding. ${ }^{29}$ That is, antecedents of exempt anaphors that c-command them might be more optimal than those that don't. Subject antecedents might be more optimal than nonsubject antecedents of exempt anaphors.

\footnotetext{
${ }^{29}$ This does not mean that exempt anaphors are restricted by structural conditions like core anaphors. It simply means that structural prominence and/or proximity of antecedents relative to the anaphor could be factors that facilitate the contextual identification of a pragmatically salient antecedent for exempt anaphors.
} 


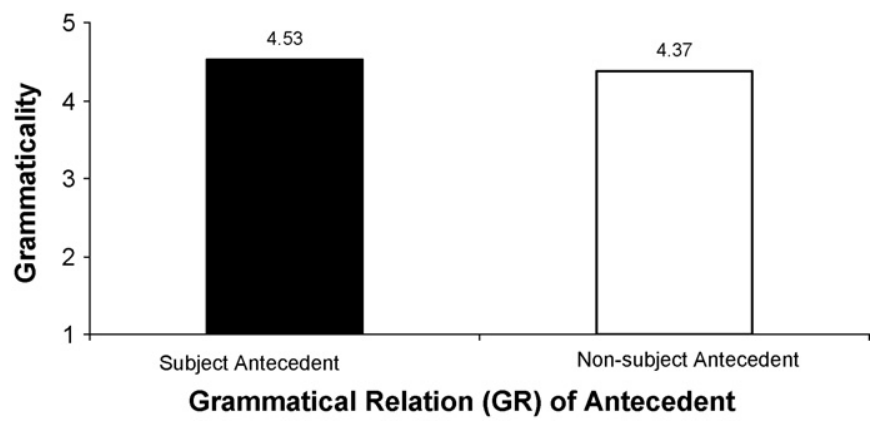

Fig. 5. Grammatical relation of LD antecedents: sentences with SOURCE antecedents.

To test this question, a portion of the target sentences was constructed so as to obtain a contrast between subject vs. non-subject antecedents and c-commanding vs. non-c-commanding antecedents. ${ }^{30}$ We held the logophoric role of the antecedent constant and manipulate the grammatical-structural factors. However, since these factors were not systematically investigated across the full range of logophoric conditions, we did not treat this question as one of the primary research questions.

The contrast between subject and non-subject antecedents was made within the sentence type that has (c-commanding) SOURCE antecedents. The examples are given below. The sentence with SOURCE antecedent presented earlier in (15) is repeated in (26a) as an example of subject antecedent, while (26b) has a non-subject antecedent, given that the local and LD subjects are not matched in features with the anaphor.

a. Inphyo ${ }_{i}$-nun $\left[\right.$ kyenchalcheng $_{j}-\mathrm{i}$ caki- casin $_{i}-\mathbf{i}$ swumki-n cungkemwul-ul chacanay-essInphyo-top police-nom self-nom hide-rel exhibit-acc find-past-ta]-ko malhay-ss-ta -decl-comp say-past-decl

'Inphyo said that the Police Agency found the exhibit he (self) had hidden.'

b. Na-nun Mary Mantheyse [mikwuk $_{\mathrm{j}}$-i pwulpep-cheylyu-hyemuy-lo caki-casin $_{\mathrm{i}}$-ul I-top Mary-from USA-nom illegal-stay-charge-for self-acc chwupangsikhi-ess-ta]-ko tul-ess-ta exile-past-decl-comp hear-past-decl $\rightarrow$ non-subject antecedent

'I heard from Mary that the USA exiled self on charges of illegal residence.'

The result of the comparison between the sentence types shown in (23a) and (23b) indicated that there was no statistically significant difference between the grammaticality score of sentences with LD subject antecedents and those with LD non-subject antecedents when the logophoric role was held constant (as SOURCE), though the former received a numerically higher score $($ mean $=4.53$, S.D. $=0.52)$ than the latter $($ mean $=4.37$, S.D. $=0.60) .{ }^{31}$ The pattern of the results with subject vs. non-subject antecedents for SOURCE antecedent is shown in Fig. 5.

The result is not surprising in view of the position taken in a number of works on exempt binding that exempt binding is not constrained by structural factors. Structural prominence (subject vs. non-subject) did not have a significant effect on the identification of potential logophoric antecedents. However, a more systematic investigation with the full range of logophoric roles is needed before a firm conclusion can be drawn.

\footnotetext{
${ }^{30}$ We attempted to contrast sentences with c-commanding antecedent and those with non-c-commanding antecedent, as we did with subject vs. non-subject antecedent. However, the way the sentences were constructed had a design flaw in that there was a confound between c-commanding vs. non-commanding condition and the subject vs. non-subject condition. Therefore, we drop this analysis from the presentation of the results.

${ }^{31}$ A one-way ANOVA showed that the responses to the sentences with subject antecedents and those with non-subject antecedents were not significantly different $[F(1,42)=3.716, p<.061, \mathrm{~ns}$.$] .$
} 


\section{Conclusion and directions for future study}

To sum up, the results of the experiments testing exempt LD binding of Korean local anaphor caki-casin show the following:

(i) Korean local anaphor caki-casin is not restricted to the domain of grammatical/core binding and can also be bound long-distance, when appropriate logophoric conditions are present.

(ii) Among distinct logophoric roles, SOURCE is more prototypical than the other two logophoric centers, while PIVOT is the least prototypical, as predicted by Sells (1987).

(iii) When the local anaphor is treated as exempt anaphor and bound by LD antecedent, strict readings in VP-ellipsis/ proform context becomes available, and may even be judged to be the dominant reading.

(iv) Contrary to previous assumptions, it may not be that all anaphors in Korean can violate the TSC. Complex, or local, anaphors such as caki-casin, may be subject to both TSC and SSC in core binding. When they appear to violate TSC and SSC, they may only do so as exempt anaphors.

(v) In the case of exempt binding, structural differences (i.e., subject vs. non-subject antecedent) do not affect judgments of acceptability, confirming the primacy of non-syntactic factors in exempt binding.

(vi) The results of the study show that even in a language with a rich inventory of anaphors (local as well as longdistance), the division of labor between the different anaphors does not coincide with core vs. exempt binding. That is, there are no anaphors that are used exclusively for core binding, with others reserved for exempt binding. Hence, the core-exempt dichotomy is orthogonal to the local vs. long-distance property of anaphors.

These results raise a number of interesting questions for further research. A pressing question that is raised by the interpretation of TSC-violating caki-casin is a follow-up experimental test of locally bound caki-casin. Although we are fairly confident that it only admits sloppy readings, we would need to back up the hypothesis with experimental data. Another experiment waiting to be performed is a systematic investigation of caki, casin, and caki-casin, in terms of both the discourse factors that facilitate long-distance binding and the interpretations of the anaphors in ellipsis and proform contexts. Although we are fairly confident that caki and casin are different from caki-casin with respect to the strict-sloppy readings when they violate tSC, we would need experimental confirmation of our confidence. It also remains to be seen if the genuine LDAs behave differently when they violate both TSC and SSC, as hypothesized for the (Taiwanese) Mandarin LDA ziji in Huang and Liu (2001).

\section{Acknowledgment}

This study is a part of a dissertation project supported by National Science Foundation (NSF) dissertation grant (ID\# 0616432; PI: Montrul, S. Co-PI: Yoon, J.).

\section{References}

Belletti, A., Rizzi, L., 1988. Psych verbs and theta theory. Natural Language and Linguistic Theory 6, 291-352.

Chomsky, N., 1980. On binding. Linguistic Inquiry 11, 1-46.

Chomsky, N., 1981. Lectures in Government and Binding. Foris, Dordrecht.

Chomsky, N., 1986. Knowledge of Language: Its Nature, Origin, and Use. Praeger, New York.

Cole, P., Hermon, G., Huang, C.-T.J., 2001. Introduction. Long-distance reflexives: the state of the art. Syntax and Semantics 33, xiii-xivii.

Cole, P., Hermon, G., Huang, C.-T.J., 2006. Long-distance anaphors: an Asian perspective. In: Everaert, M., van Riemsdijk, H., Goedemans, R., Hollebrandse, B. (Eds.), Blackwell Companion to Syntax, vol. 3. Blackwell Publishers.

Cole, P., Hermon, G., Sung, L.-M., 1990. Principles and parameters of long-distance reflexives. Linguistic Inquiry 21, 1-22.

Goldwater, M., Runner, J., 2006. Coreferential interpretations of reflexives in picture noun phrases: an experimental approach. Proceedings of the Texas Linguistics Society.

Han, C., Lidz, J., Musolino, J., 2007. V-raising and grammar competition in Korean: evidence from negation and quantifier float. Linguistic Inquiry 38,1 .

Huang, C.-T.J., Liu, C.-S.L., 2001. Logophoricity, attitude, and ziji at the interface. Syntax and Semantics 33, 141-195.

Huang, Y., 2000. Anaphora: a cross-linguistic study. In: Oxford Studies in Typology and Linguistic Theory, Oxford University Press.

Iida, M., 1992. Context and binding in Japanese. PhD Thesis. Stanford University. California.

Kang, B.-M., 1998. Grammar and the use of language: Korean reflexives 'caki', 'casin', and 'caki-casin'. Kwukehak 31, $165-204$. 
Katada, F., 1991. The LF representation of anaphors. Linguistic Inquiry 22, 287-313.

Kim, J.-H., Montrul, S., 2004. Binding interpretations in Korean heritage speakers. In: Proceedings of the 28th Boston University Conference on language Development. Cascadilla Press, Somerville, MA, pp. 306-317.

Kim, S.-W., 1999. Strict/sloppy identity, empty objects, and NP ellipsis. Journal of East Linguistics 8, 255-284.

Lee, K.-Y., 2007. The role of pragmatics in reflexive interpretation by Korean learners of English. In: Paper presented at the 2007 Second Language Research Forum. University of Illinois, Urbana-Champaign.

Maling, J., Jun, J.-S., Kim, S.-W., 2000. Case-marking on durational adverbials revisited. In: Ahn, H.-D., Kim, N.-K. (Eds.), Selected Papers from the Twelfth International Conference on Korean Linguistics. Kyungjin Mwunhwasa, Seoul, pp. 323-335.

Oshima, D., 2006. On empathic and logophoric binding. Research on Language \& Computation 5, 19-35.

Otani, K., Whitman, J., 1991. V-raising and VP-ellipsis. Linguistic Inquiry 22, 345-358.

Pollard, C.J., Sag, I.A., 1992. Anaphors in English and the scope of binding theory. Linguistic Inquiry 23, 261-303.

Pollard, C.J., Sag, I.A., 1994. Head-driven Phrase Structure Grammar. The University of Chicago Press and CSLI Publication, Chicago and Stanford.

Pollard, C., Xue, P., 2001. Syntactic and non-syntactic constraints on long-distance reflexives. In: Peter, C., Hermon, G., Huang, J. (Eds.), Long Distance Reflexives. Syntax and Semantics Series. Academic Press, pp. 317-342.

Reinhart, T., Reuland, E., 1993. Reflexivity. Linguistic Inquiry 24, 657-720.

Runner, J.T., Sussman, R.S., Tanenhaus, M.K., 2002. Logophors in possessed picture noun phrases. In: Mikkelsen, L., Potts, C. (Eds.), WCCFL 21 Proceedings. Cascadilla Press, Sommerville, MA, pp. 401-414.

Runner, J.T., Sussman, R.S., Tanenhaus, M.K., 2006. Processing reflexives and pronouns in picture noun phrases. Cognitive Science 30, $193-241$. Sells, P., 1987. Aspects of logophoricity. Linguistic Inquiry 18, 445-479.

Yang, D.-W., 1983. The extended binding theory of anaphors. Language Research 19, 169-192.

Yoon, J.-M., 1989. Long-distance anaphors in Korean and their crosslinguistic implications. Chicago Linguistic Society 25: General Session 479495. 